\title{
Characterization of bedload discharge in bores and very unsteady flows in an ephemeral channel
}

\author{
Eran Halfi ${ }^{1,2}$ Vishal Deshpande ${ }^{2}$, Joel P. L. Johnson ${ }^{3}$, David Katoshevski ${ }^{1}$, Ian Reid ${ }^{4}$, \\ Yael Storz-Peretz ${ }^{2}$ and Jonathan B. Laronne ${ }^{2}$ \\ ${ }^{1}$ Ben-Gurion University of the Negev, Unit of Environmental Engineering, Israel \\ ${ }^{2}$ Ben-Gurion University of the Negev, Geography and Environmental Development, Israel \\ ${ }^{3}$ The University of Texas at Austin, Geological Sciences, U.S.A \\ ${ }^{4}$ Loughborough University, Geography, England
}

\begin{abstract}
Bedload flux under steady flow conditions is calculated by a multitude of available methods and equations. Yet, very little is known about the effect of very unsteady flows, such as flash floods and specifically bores, on bedload flux. The unpredictable nature of the floods together with many logistic difficulties and safety issues in monitoring explain this gap in knowledge. Global climate change may increase flood event occurrence, making their understanding even more crucial. The methodology of our study is based on automatically monitoring bedload flux (Reid slot samplers). Automation allowed high frequency monitoring of hydraulic parameters and bedload flux. Added novelty includes pipe and plate microphones for capturing acoustic signals of bedload sediments and 3-D velocimetry for characterizing turbulence. Alerting sensors and cellular data transmission enabled onsite presence upon bore arrival. Calibration between the acoustic indirect sensors and the direct slot samplers allows determination of bedload flux at a frequency of $1 \mathrm{~Hz}$. Analyses of flood events indicate an increase in turbulent kinetic energy, instantaneous vertical velocities, shear stress and bedload flux during the rising limb within the first two minutes after bore arrival. This has implications for the likely destabilization of the channel bed and for bedload transport after passage of the bore and during subsequent, less unsteady flows.
\end{abstract}

\section{Introduction}

Sediment movement impacts channel stability, topography, water quality, habitats, agricultural areas and structures such as bridges and highways as well as nearby buildings. Among the different types of fluvial sediment transport, bedload transport is most difficult to monitor. Therefore, there is a knowledge gap in this field in terms of predicting fluxes and understanding dynamics. Extrapolation of observations from flumes or small discharges does not allow proper predictions of bedload movement in high, turbid, or rapidly changing flows [1]. Development of effective, continuous, and automatic means for bedload monitoring will improve the knowledge and understanding of bedload dynamics [2]. With few exceptions based solely on flume experimentation $[3,4,5,6]$, little is known about the effect on bedload flux of very unsteady flows such as dam breaks $[7,8]$ and desert flash floods. Our study focuses on natural flash floods, where discharge rapidly changes as a flood bore arrives on a dry river bed (Figure 1). 


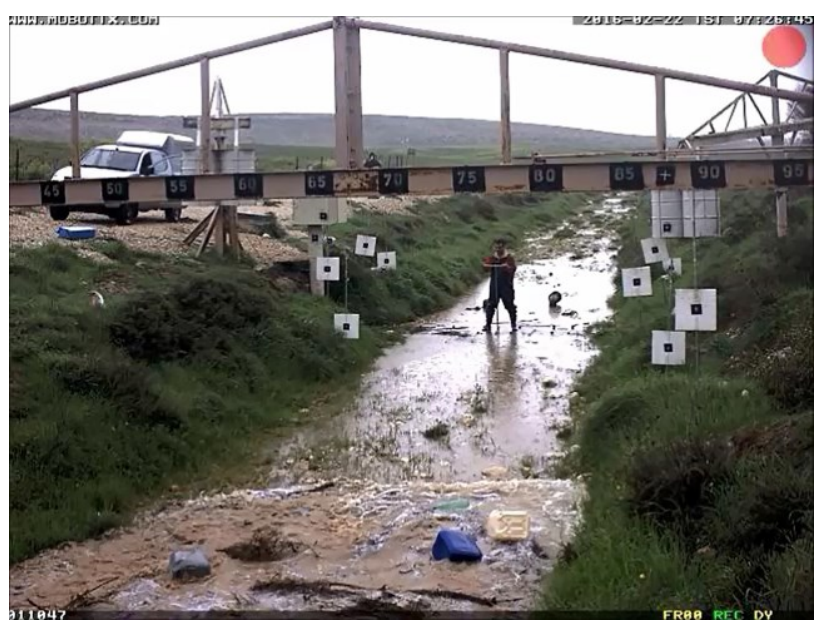

Fig. 1. Downstream view of bore arrival in Nahal Eshtemoa, 22.02.2016.

\section{Methods}

\subsection{Research area}

The study is conducted in Nahal Eshtemoa, an ephemerally flowing river with a drainage area of $112 \mathrm{~km}^{2}$ at the gauging station. The regional climate is semi-arid with an average annual precipitation of $280 \mathrm{~mm}$ occurring mostly during winter and an annual frequency of 0-6 flow events. The channel width at the gauging station is $5 \mathrm{~m}$, the river bed is mostly gravel with a matrix of $2-10 \%$ sand. Monitoring shows that over the past few years the amount of silt and clay in the bed has increased, adding cohesion, adhesion and stability to the riverbed [9]. The channel alternates between flats and bars, with grain size $d_{50}=17 \mathrm{~mm}$ in the flat and $98 \mathrm{~mm}$ in the bar of the approach reach [10]. The majority of the bed excluding the bars is unarmored.

\subsection{Instrumentation}

Our methodology is based on the demonstrated ability of the Nahal (Wadi) Eshtemoa gauging station to automatically monitor bedload flux, water depth and water surface slope. The instrumentation used for previous studies was unable to quantify changes in flow characteristics and bedload flux at a high temporal resolution, such as the first seconds of a bore front. For this study, novel equipment has been added to the station with the ability to monitor at high time resolution. Additional to these, a data transmission alert system was installed to enable researchers to be on site when a flood bore arrives.

\subsubsection{Water characteristics}

Vented pressure transducers and a 3-D electromagnetic current meter (ECM) were used for monitoring the flow depths and velocities of the bores. Vented pressure transducers (Druck; $5 \mathrm{~mm}$ precision) are installed in stilling wells located along the channel banks (six on the left bank and three on the right) between the gauging station and as far as $170 \mathrm{~m}$ upstream. This enables us to calculate temporal variations of water depth and surface water slope. An ECM type ACM3-RS (Alec Electronics) with measuring frequency of $40 \mathrm{~Hz}$ was 
deployed $8 \mathrm{~cm}$ above the river bed. The ECM measures flow velocities in three dimensions and enables the determination of turbulence characteristics.

\subsubsection{Bedload Transport}

For measuring bedload transport, direct and indirect sampling methods are used. Automatic Reid-type bedload slot samplers directly monitor bedload. Japanese pipe/plate microphones are used for indirect monitoring $[11,12]$.

\section{Reid-type automatic slot samplers}

Three independent Reid-type slot samplers monitor bedload flux, covering the cross section of the channel at the gauging station. The width of each slot is adjusted to $110 \mathrm{~mm}$, equivalent to $D_{90}$ of the bed material in the approach reach. The advantages of the instrument lie in direct and continuous measurement and long experience in measuring bedload flux in Nahal Eshtemoa and other rivers worldwide. Its two main disadvantages are (a) the limited capacity of the collecting box, which makes it impossible to measure during the entire duration of a long-duration flow event, and (b) the relatively low measurement accuracy of approximately $2 \mathrm{~kg}$, which makes it difficult to accurately measure transport rates at high temporal resolutions during rapidly changing flows such as flood bores.

\section{Acoustic samplers: plate and pipe microphone}

Two types of acoustic sensor are deployed. Both operate on a similar principle: a sediment collision with the sensor generates an electric current proportional to the intensity of the energy of the encounter, which is proportional to grain size, but also dependent to some extent on the angle of attack, on the height of fall and on the location on the sensor [12]. The advantages of the acoustic systems are: A) there is no capacity limit as in the slot sampler; therefore, the entire duration of a flood can be monitored; and B) they have high sensitivity, with a detection grain-size threshold of approximately $4 \mathrm{~mm}$ [12]. Therefore, these sensors are suitable for higher time resolution; a requisite for understanding bore front processes. Their disadvantage is that as they are a surrogate measuring technique and they require calibration against the direct slot samplers to determine bedload fluxes. Calibration between these two instruments was undertaken in Nahal Eshtemoa yielding $\mathrm{r}^{2}=0.76$ (Figure 2), acceptably high for a field study, where a large number of parameters can influence the quality of calibration.

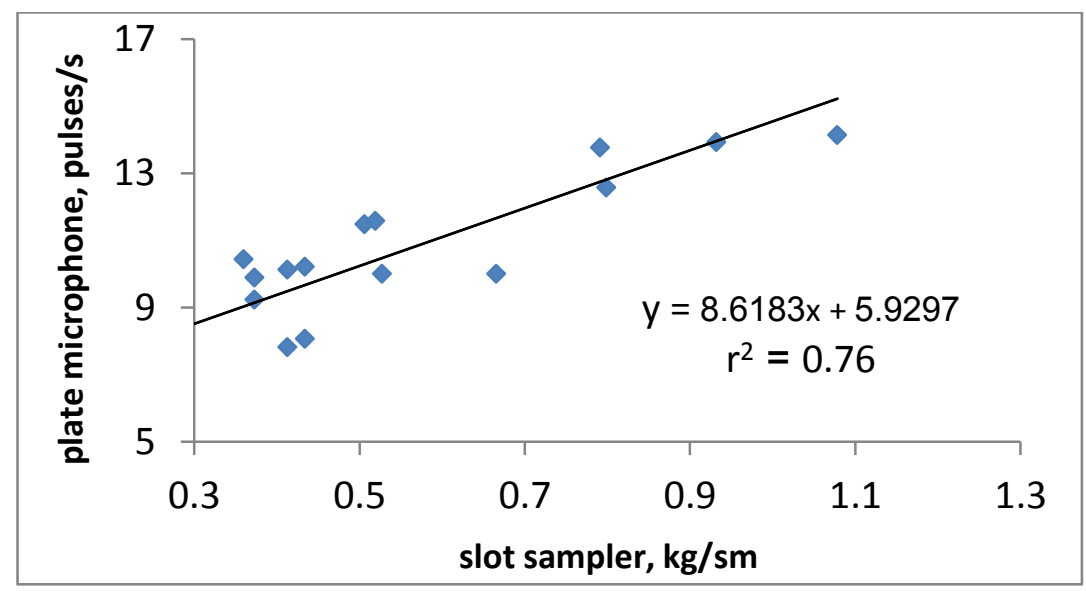

Fig. 2. Calibration curve between pulse rates monitored by the plate microphone and bedload flux. 


\section{Results and discussion}

Representative results of the flow and bedload characteristics during flashflood bore passage are presented in this section for one flood occurring in February 2016.

\subsection{Flow characteristics}

During bore advance, the flow is unsteady and water slope varies considerably with time. The water slope is prominent for determining the magnitude of the shear stress acting on the river bed [13]. Therefore, it has a direct effect on bedload transport. In the February 2016 event, the water slope of the bore arriving at the gauging station was as much as 2.2 and 2.3 times the magnitude of the water slope at maximum depth and during recession (Figure 3). These larger slopes generate an increased shear stress on the bed in comparison with similarly shallow water depths in gradually varying flow. This is in agreement with both theory and studies demonstrating that calculating the average reach shear stress is insufficient for unsteady flows $[14,15]$.

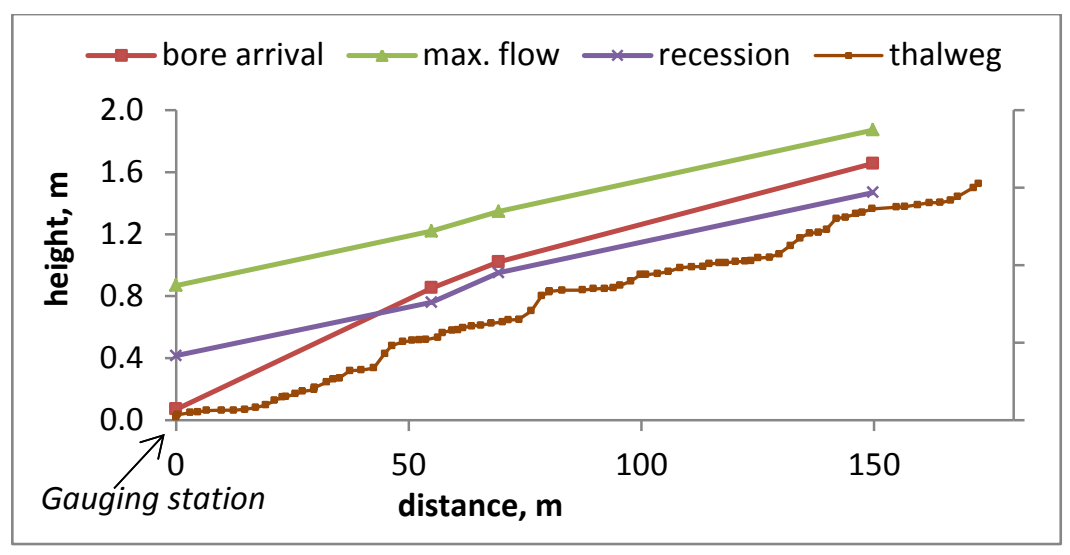

Fig. 3. Water surface slopes: during bore arrival $(1.42 \%)$, maximum water depth $(0.63 \%)$ and recession $(0.64 \%)$ as well as the riverbed slope $(0.89 \%)$. The slopes (and time of occurrence) refer to the reach $150 \mathrm{~m}$ upstream of the gauging station.

For turbulence characterization this study uses a 3-D ECM to measure water velocity in three dimensions: longitudinal, horizontal and vertical in the middle of the channel at $8 \mathrm{~cm}$ above the river bed. Several studies demonstrate the important contribution of vertical velocities to sediment transport in enhancing lift forces. Figure 4 demonstrates a higher magnitude of the vertical velocities in the first 40 seconds after bore arrival. These velocities are as much as four times larger than those typical of the flow conditions after passage of the flood bore.

The turbulent kinetic energy (TKE) is the kinetic energy of the turbulent fluctuations per unit mass of the moving fluid $\left[\mathrm{J} / \mathrm{kg}=\mathrm{m}^{2} / \mathrm{s}^{2}\right]$. It represents the intensity of turbulence [16]. Analysis of bore arrival reveals higher TKE values during the first 20 seconds of bore rise (Figure 5). High energy losses due to the strong friction generated by the flashflood bore moving on a dry river bed manifests itself in a highly turbulent flow and high values of TKE. 


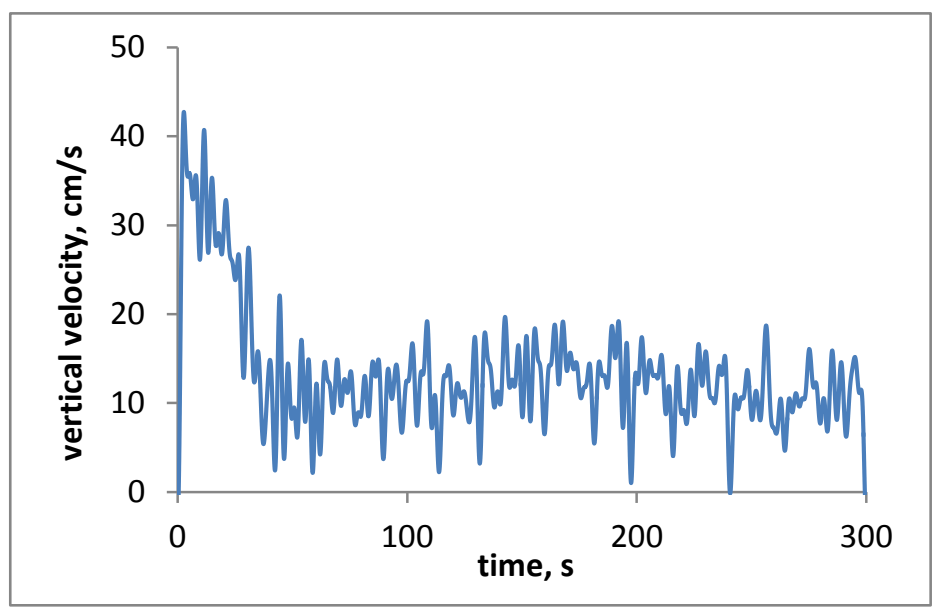

Fig. 4. Vertical velocity measured at $40 \mathrm{~Hz}$ by the ECM. Time 0 represents bore arrival over a dry river bed. The dashed line is the average vertical post-bore velocity.

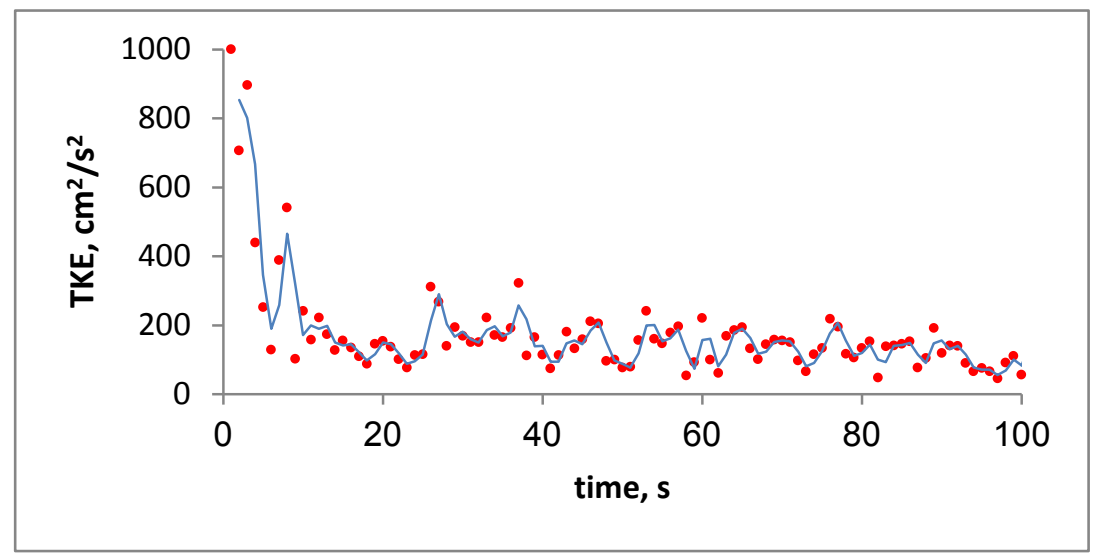

Fig. 5. 1s-averaged TKE values during bore arrival over a dry river bed. The blue line represents the arithmetic average and the black dashed line represents the moving post-bore average. Time 0 represents bore arrival over a dry river bed.

\subsection{Bedload transport}

Direct and indirect measurements of bedload transport were conducted during the flood season, thereby allowing calibration of the acoustic sensors (Figure 1). This enabled us to convert the pulse data to bedload flux ( $\mathrm{kg} / \mathrm{sm})$, and thereby to monitor bedload flux at high temporal resolution. Figure 6 demonstrates the response of bedload transport to the imposed turbulence generated by the bore (Figure 5). Bedload flux is high during bore arrival and thereafter decreases even though water depth increases. 


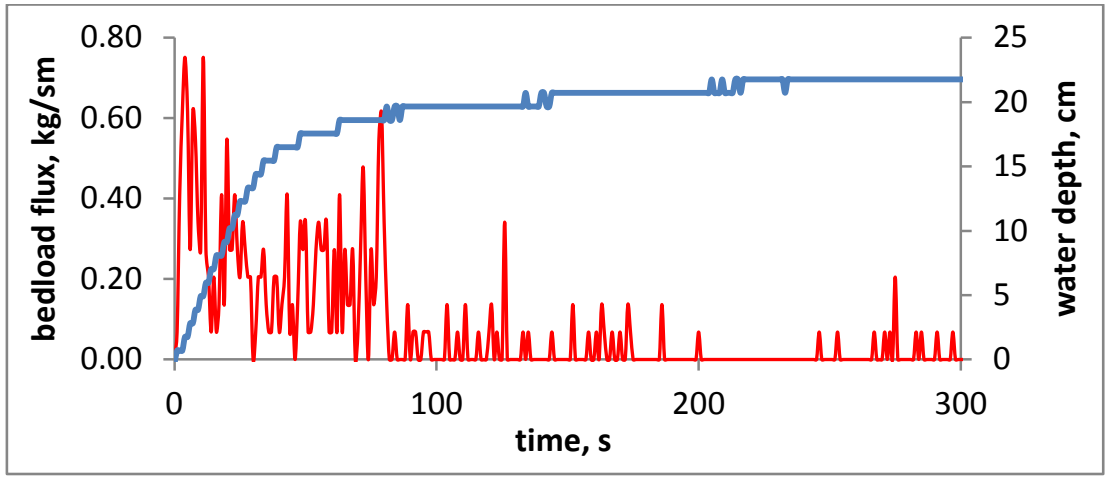

Fig. 6. Calibration-based (plate microphone) bedload flux during bore arrival. Time 0 represents bore arrival over a dry river bed.

\section{Summary}

Hydrodynamic characteristics of flow and bedload transport have been monitored in Nahal Eshtemoa during flashflood bore arrival. The rapid increase in water depth (during bore arrival) gives rise to high vertical velocities and high turbulent kinetic energy. The calibration of the pipe microphone allowed, at high frequency, identification of bedload response to the imposed vertical velocities and turbulence. Turbulence thus plays a crucial role in bedload transport within the short duration of bore arrival in relatively shallow flow, when, otherwise using a depth-slope product to calculate shear forces, no bedload transport would be expected to occur. This affects the stability of the channel bed, reordering and disaggregating it for subsequent transport, particularly in the more stable, slightly-armoured bars [17], but also in the intervening flats despite the adhesion and cohesion provided by their fine-grained matrix [9]. This process of channel-bed disturbance is also relevant to dam break situations.

\section{Acknowledgements}

This study was supported by the Israel Science Foundation ISF, grants 1073/09 and 832/14.

\section{Bibliography}

1. S. J. Bennett, P. Ashmore and C.M. Neuman, Transformative geomorphic research using laboratory experimentation. Geomorphology, 244, 1-8 (2015)

2. J. R. Gray, J.B. Laronne, J.D.G. Marr, Bedload-surrogate monitoring technologies: US Geological Survey Scientific Investigations Report 2010-5091, 37 p. (2010)

3. R. De Sutter, R. Verhoeven, A. Krein, Simulation of sediment transport during flood events: laboratory work and field experiments. Hydrological Sciences Journal, 46(4), 599-610 (2001)

4. K. T. Lee, L. Y. Liu, K. H. Cheng, Experimental investigation of bedload transport processes under unsteady flow conditions. Hydrological Processes, 18(13), 24392454 (2004) 
5. K. P. Pathrina, P. C. Ranasinghe, U. R. Ratnayake, ). Influence of reference bed level on computation of bed shear stress in open channel flow. Engineer: Journal of the Institution of Engineers, Sri Lanka, 39(3) (2006)

6. M. K. Tabarentani, R. A. Zarrati, Sediment transport during flood event: a review. International Journal of Environmental Science and Technology, 12(2), 775-788 (2015)

7. M. Emmett, T. B. Moodie, Dam-break flows with resistance as agents of sediment transport. Physics of Fluids, 20(8), (2008)

8. Y. Zech, S. Soares- Frazão, B. Spinewine, N. Le Grelle, Dam-break induced sediment movement: experimental approaches and numerical modelling. Journal of Hydraulic Research, 46 (2), 176-190 (2008)

9. R. Barzilai, J. B. Laronne, I. Reid, Effect of changes in fine-grained matrix on bedload sediment transport in a gravel-bed river. Earth Surface Processes \& Landforms, 38(5), 441-448 (2012)

10. H. Cohen, J. B. Laronne, I. Reid, Simplicity and complexity of bed load response during flash floods in a gravel bed ephemeral river: a 10 year field study. Water Resources Research, 46(11) (2010)

11. T. Mizuyama, J. B. Laronne, M. Nonaka, T. Sawada, Y. Satofuka, M. Matsuoka, S. Yamashita, Y. Sako, S. Tamaki, M. Watari, S. Yamaguchi, K. Tsuruta, Calibration of a passive acoustic bedload monitoring system in Japanese mountain rivers. U.S. Geological Survey Scientific Investigations Report SIR 2010-5091, 296-318 (2010)

12. T. Mizuyama, A. Oda, J.B. Laronne, M. Nonaka, M. Matsuoka, Laboratory tests of a Japanese pipe geophone for continuous acoustic monitoring of coarse bedload. U.S. Geological Survey Scientific Investigations Report, 5091, 319-335 (2010)

13. L. Meirovich, J. B. Laronne, I. Reid, The variation of water-surface slope and its significance for bedload transport during floods in gravel-bed streams. Journal of Hydraulic Research, 36(2), 147-157 (1998)

14. H. Tu, W. H. Graph, Vertical distribution of shear stress in unsteady open-channel flow. Proceedings of the Institution of Civil Engineers: Water Maritime and Energy, 96, 63-9 (1992)

15. K. P. Pathirana, P. C. Ranasinghe, U. R. Ratnayake, Bed shear stress in unsteady open channel flow over rough beds. Engineer: Journal of the Institution of Engineers, Sri Lanka, 41(1) (2008)

16. S. Day, Fluvial Hydrodynamics: Hydrodynamic and Sediment Transport Phenomena. Springer (2014)

17. J. B. Laronne, I. Reid, Y. Yitshak, L. E. Frostick, The non-layering of gravel streambeds under ephemeral flood regimes. Journal of Hydrology, 159, 353-363 (1994) 